\title{
MRS enhances commitment to spreading the word about materials
}

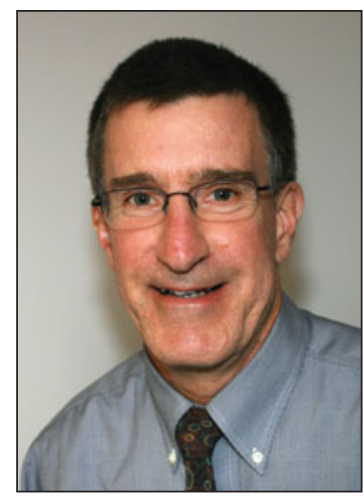

Bruce M. Clemens 2012 MRS President

Mission: The Materials Research Society is an organization of materials researchers from academia, industry, and government that promotes communication for the advancement of interdisciplinary materials research to improve the quality of life.

Vision: The Materials Research Society will build a dynamic, interactive, global community of materials researchers to advance technical excellence by providing a framework in which the materials disciplines can convene, collaborate, integrate, and advocate.
First, I want to thank you for providing me with the privilege to help lead the Materials Research Society this year as President. From my first meeting attended back in the 1980s, I have always found MRS to be an exciting, open, and innovative front-runner in the dissemination of materials science information. From my involvement as a 2001 MRS Fall Meeting Chair to service on the Board of Directors in 2002-2004 to this past year as vice president, I have continued to be impressed by the dedication and passion of the talented volunteers and staff who make this Society unique.

One outstanding and ongoing hallmark of MRS has been its commitment to highlight the latest cutting-edge materials research. This has always been evident in its Spring and Fall Meetings, which have a palpable "buzz" created by our presenters and attendees. Over the years, this dedication to inform and engage the materials community has expanded in scope to include increased advocacy, professional development opportunities, public outreach efforts, and a broadening publications portfolio-all in the spirit of fulfilling the Society's mission and vision.

With the expansion of activities, the Board decided to undertake a new initiative - a strategic look at the types of meetings and/or enhancements to the current meetings that would best serve the global research community. The intent is to create a comprehensive Meetings Portfolio to provide guidance for "meetings" decisions based on a long-term plan to provide various types of information to the community.

At the 2011 MRS Fall Meeting, we met with the MRS operating committee members and meeting attendees to obtain their suggestions and comments, and to understand the current needs of the scientific community. The participants' feedback largely focused on virtual technologies and how these technologies could enhance MRS meetings and other activities, which demonstrates that the community would welcome new and innovative methods of information delivery. The possibilities are exciting and endless! As we move forward with this initiative, we will be asking for your thoughts and ideas, and we encourage your continued input.

I am looking forward to my year as President. I see many great opportunities and ventures ahead, and I hope you will take an opportunity to let me know your thoughts, so we can all see the fruits of our ideas and efforts, in the next few years.

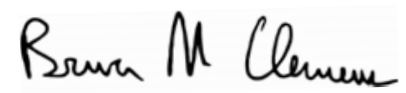

Bruce M. Clemens

2012 MRS President 